\title{
Prevention of reflux after esophagectomy with endoscopic negative pressure therapy using a new double-lumen open-pore film drainage with an intestinal feeding tube
}

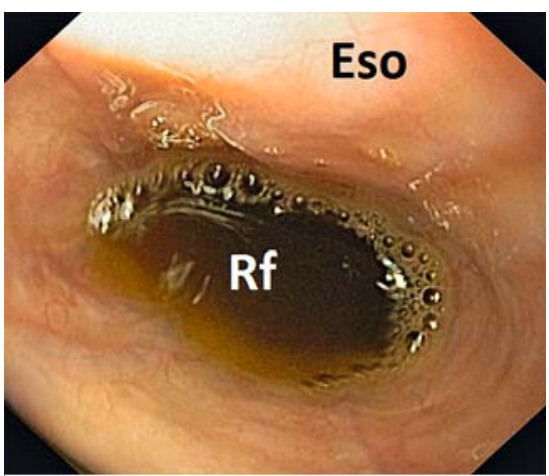

Fig. 1 Biliary gastric reflux (Rf) is flooding the anastomosis in the esophagus (Eso) of a 70-year-old patient who has undergone Ivor Lewis esophagectomy.

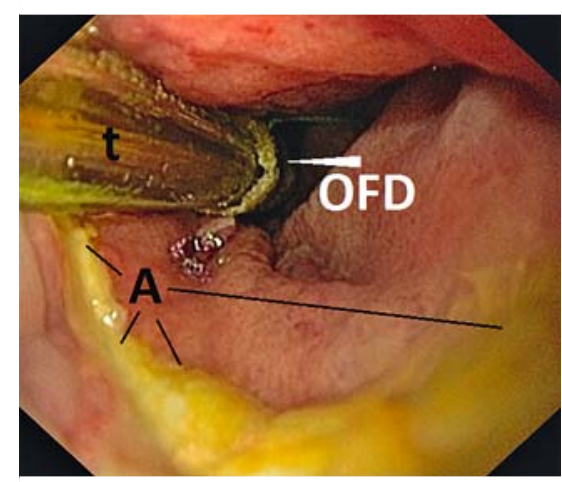

Fig. 4 The tube (t), with the open-pore film drainage (OFD) section placed in the stomach distal to the anastomosis (A), for simultaneous endoscopic negative pressure therapy to drain biliary reflux, and intestinal feeding via the duodenum.

Reflux after Ivor Lewis esophagectomy has a deleterious effect on anastomotic wound healing and is a risk for pulmonary aspiration [1]. We report endoscopic negative pressure therapy, using a novel double-lumen open-pore film drainage method, for prevention of postoperative reflux.

A 70-year-old patient underwent Ivor Lewis esophagectomy because of carcinoma of the distal esophagus (pT2pN0),

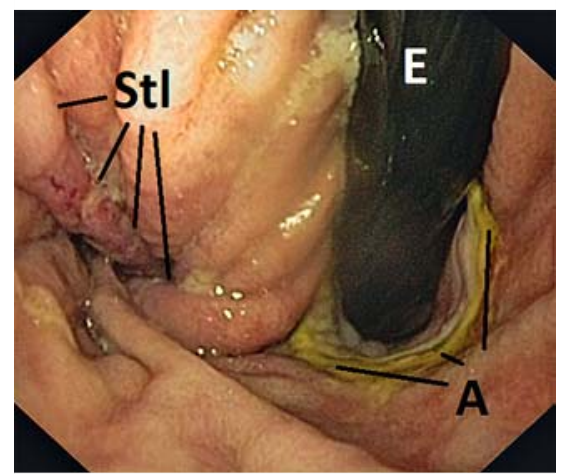

- Fig. 2 Retroverted view shows the green-colored anastomosis (A), inflammation at the gastric staple line (StI), and the endoscope (E).

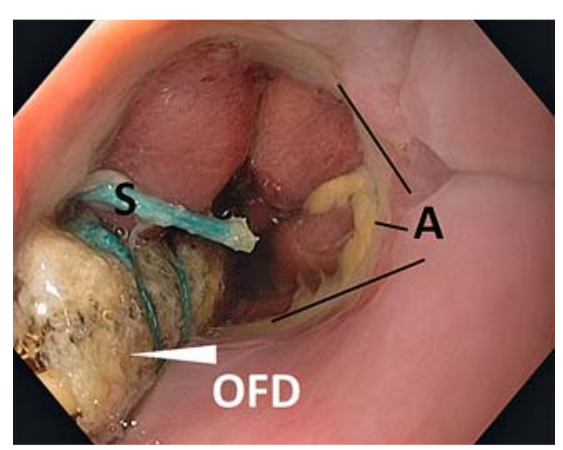

- Fig. 5 Change of open-pore film drainage device (OFD) after 3 days of endoscopic negative pressure therapy. The stomach is empty, no biliary reflux is seen, and the green coloration of the anastomosis (A) has disappeared. S, suture.

having undergone laryngectomy because of carcinoma of the larynx 5 years previously. On postoperative day 4 , rising inflammatory parameters led to endoscopy in order to check the anastomosis, in accordance with our treatment algorithm [2]. We found biliary gastric reflux flooding the intrathoracic anastomosis ( Fig. 1). The anastomotic tissue was seen to be green-colored and the staple line of the stomach showed signs of inflammation ( Fig. 2).

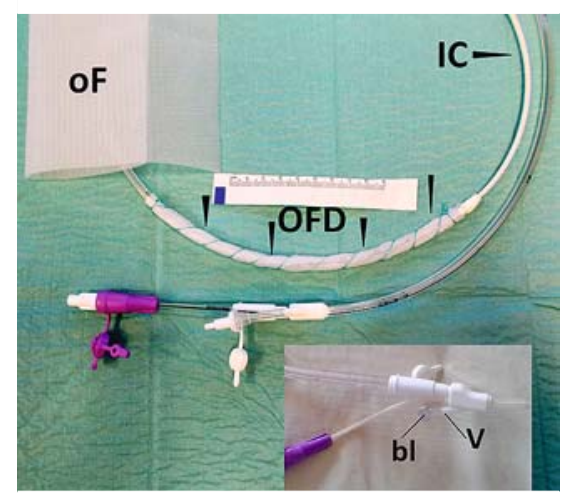

- Fig. 3 Double-lumen open-pore film drainage (OFD) device with intestinal feeding channel (IC), adapted from a triluminal tube by means of open-pore film (oF). The (ventilation) lumen $(\mathrm{V})$ is blocked with a clamp (bl).

We decided to evacuate the stomach with endoscopic negative pressure therapy, using an innovative double-lumen drainage system that incorporated open-pore film material. Our goal was to eliminate the postoperative reflux that was compromising the anastomotic healing.

We adapted a triluminal tube (Freka Trelumina, CH/Fr 16/9, $150 \mathrm{~cm}$; Fresenius, Germany) using open-pore film (Suprasorb CNP Drainagefolie; Lohmann and Rauscher, Germany). All the openings of the gastric channel of the triluminal tube were wrapped around once with a length of the open-pore film. The film was fixed using suture thread. The ventilation lumen of the tube was blocked

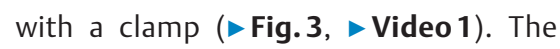
small-bore tube was inserted nasally and pushed, so that finally the intestinal feeding channel was positioned in the duodenum ( Video 1 ) and the filmwrapped part of the tube was positioned in the stomach ( $>$ Fig. 4 ).

Application of negative pressure with an electronic device (setting - $125 \mathrm{mmHg}$, continuous, intensity 10; KCI V.A.C. Freedome, KCI USA Inc., San Antonio, Texas, 


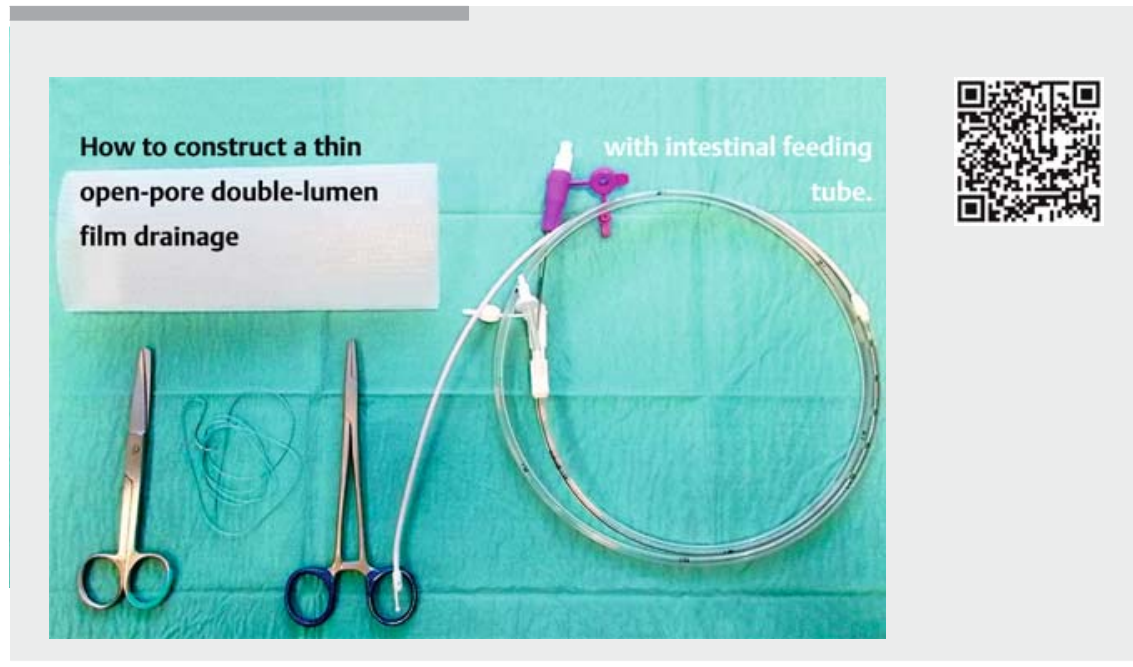

$\checkmark$ Video 1 The construction of a double-lumen open-pore film drainage (OFD) device and the course of endoscopic negative pressure therapy (ENPT) for preventing gastric reflux after Ivor Lewis esophagoectomy.

USA) resulted in permanent collapse of the stomach and complete drainage of the reflux. Simultaneously, intestinal nutrition was started along the feeding channel. The open-pore film drainage was changed once after 3 days of treatment ( Fig.5). Infection signs at the staple line and green colored imbibition at the anastomosis had disappeared. Endoscopic negative pressure therapy was ended after a period of 10 days. Follow-up endoscopy 7 days after the end of therapy showed complete healing ( $\vee$ Video 1 ).

Double-lumen open-pore film drainage combined with the intestinal feeding tube enables full enteral nutrition and complete gastric drainage, simultaneously. The active prevention of reflux with double-lumen open-pore film drainage is an easy method of supporting ana-

\section{Christian T. Müller}

Corresponding author

\section{Gunnar Loske, MD}

Katholisches Marienkrankenhaus Hamburg gGmbH, Department for General,

Abdominal, Thoracic and Vascular Surgery, Alfredstrasse 9, 22087 Hamburg, Germany Fax: +49 (0)4025461400

loske.chir@marienkrankenhaus.org

\section{Acknowledgments}

We would like to thank the nursing staff of the interdisciplinary endoscopic unit of Marienkrankenhaus-Hamburg for their excellent technical assistance. We also wish to thank our colleagues from the intermediate care unit for their good and helpful cooperation.

\section{References}

stomotic healing after esophageal resection.

Endoscopy_UCTN_Code_TTT_1AO_2AJ

\section{Competing interests}

Gunnar Loske is a consultant to Lohmann \& Rauscher GmbH. Tobias Schorsch and Christian Theodor Mueller declare no conflict of interest.

\section{The Authors}

\section{Gunnar Loske, Tobias Schorsch,}

Department for General, Abdominal, Thoracic and Vascular Surgery, Katholisches Marienkrankenhaus, Hamburg, Germany vacuum therapy of perforations and anasto-
[1] Chen KN. Managing complications I: leaks, strictures, emptying, reflux, chylothorax. J Thorac Dis 2014; 6: S355-S363

[2] Schorsch T, Müller C, Loske G. Endoscopic motic insufficiency of the esophagus. Chirurg 2014; 85: 1081 - 1093

\section{Bibliography}

DOI https://doi.org/10.1055/s-0043-118211

Published online: 19.9.2017

Endoscopy 2017; 49: E294-E295

(c) Georg Thieme Verlag KG

Stuttgart · New York

ISSN 0013-726X

\section{ENDOSCOPY E-VIDEOS}

https://eref.thieme.de/e-videos

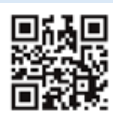

Endoscopy E-Videos is a free access online section, reporting on interesting cases and new

techniques in gastroenterological endoscopy. All papers include a high quality video and all contributions are freely accessible online.

This section has its own submission website at https://mc.manuscriptcentral.com/e-videos 